\title{
Educational Planning and Human Resource Management: A Study of Public and Private Schools in Pakistan
}

\author{
Adeela Rehman \\ Fatima Jinnah Women University, Rawalpindi, Pakistan \\ adeela.rehman@fjwu.edu.pk
}

\begin{abstract}
Planning and management of curriculum and human resources in schools is precisely liable and precarious in nature. The present study addressed the matter while exploring the practices of educational planning and human resource management in public and private primary level schools in Punjab, Pakistan. The case studies of two public and private schools in Rawalpindi District of Punjab Province were conducted by interviewing the mangers and principles of private and public school respectively. The participant observations were also taken to substantiate the information provided by the respondents. The schools were selected on the basis of their reputation and high enrollment of the students. The findings of the study elaborated the differences in public and private schools with respect to educational planning and managing human resource. The public schools followed the standard curriculum designed by the Punjab text book board which is universal for all the public schools. The teachers are mostly on permanent position and experienced. Whereas in the private schools, international level curriculum is followed this differs from school to school. Every private school has their own curriculum which they followed according to the standard of the school. The manager of the school generally decides the nature of the curriculum and recruitment of the teacher on its own will and interests. The medium of instruction is English in private schools, while public school used both national and international language. As far as teacher competence is concern, the public school teachers are more experienced as compare to private schools as they are working at the same school for a longer time period due to which better able to manage various task in the school and also take part in educational planning. On the other hand, in private school, fresh and most of the time untrained young females are hired. For these employees, professional development and retention is very important for the managers. Selecting and recruiting new teacher is very tedious job as well as it also affects the student's performances and achievements. It is indicated that the owner of the private school was in continues struggle and in apprehension of hiring, and retaining their staff by providing them extra bonuses and facilities at school, such as leaves, time flexibility, and reward etc.
\end{abstract}

Keywords: Educational Planning, Management, Public School, Private School.

\section{Introduction}

Educational planning and human resource management is the essential job for all schools across the globe. Planning and management involves coordination, organization, monitoring and evaluations of different tasks of the school particularly with respect to educational planning which is the most imperative concern (Suleman et al., 2012). Educational planning and management is known as the practices of selecting, designing and implementing the standardized and contemporary curriculum. The tasks are performed by a team comprises of principles, directors, teachers and related personnel. Ball (1990) defined educational planning is the important foundation stone for the development of a society. Nations progress on the development of their education system. Human resource Management is defined as management of people working in any organization. It is a managerial function, role or responsibility fulfill the goals of an organization by selecting and recruiting relevant and potential employees. It is the responsibility of hiring human resources in specific organization, institute, school etc. as well as helping them to perform their work and solve their problems that rise. Like any other organization and institutes, private schools also focused of human resource management. The education system in Pakistan is distant from such development and advancement due to feeble and distracted education system. Zafar (2003) highlighted the factors such as; corrupt bureaucracy, authoritarian organizations, inelastic civil society and weedy democracy contributing to make the system fragile and scrawny. Various studies have indicated that involving private schools in education has been successful efforts by the government of Pakistan, as public sector cannot fulfill all the demands and needs of the masses (Andarabi et al., 2002). 
For nation building and progression, Pakistan is unsuccessful to produce effective human resource. There are three types of education system working in Pakistan i.e.; Public, private and 'Madrash' (Religious Education). There is not only a huge difference in three types of education system with respect to economic resources but also in provision of teaching and quality of the education faculties provided in respective institutions (The Nation, 2018). The provision of basic education is the prime responsibility of any government which is established through public schools. As the government in developing nations alone cannot fulfill the needs of the entire population, therefore private schools is increasing rapidly to meet the desired outcomes for the nation (Coulson, 2003). Private schools are competently occupied to expand the literacy rate and quality of education. The establishment of expanded excellence in education in private schools parents preferred them. Private schools have lower student teacher ratio, small buildings, less human resource and required small infrastructure to start the school. But within the limited financial resources, it is perplexing to full fill the objectives of the institute and accomplish all the resources (Andarabi et al., 2002). For private schools, Human Resource Management is the process of recruitment, section of employee, providing proper orientation and induction, providing training and the developing skills, assessment of employee (performance of appraisal), providing compensation and benefits, maintaining proper reaction among employees etc. the present study aimed to explore the issue and challenges encountered by the public and private schools with respect to educational planning and human resource management.

\section{Methodology}

The qualitative study design was used to conduct interviews from the school managers and principle from private and public schools respectively. The case study method was employed to meet the objectives of the research. Two public and two private schools in Rawalpindi district of Punjab province were selected by using convenient sampling technique. The self-constructed interview guideline was use to conduct interviews from the targeted respondents. The confidentially of the school names and identity of the respondent was assured the interviews were audio recorded with the permission of the respondents, by using verbatim analysis the interviews were transcribed into English and the findings are presented by adopting thematic analysis. To verify the information obtained, some participants' observation was also made to triangulate the study.

\section{Results and Discussion}

Based on the personal experience, observation and conducting interview from the manager of the schools, the results of the study are explained under following themes:

Curriculum Planning in Schools: Curriculum planning is one the most important task taken into consideration in educational management. In most of the public schools in Punjab Pakistan, the curriculum is advised by the government and ministry of education. The educationist from across the country designed the curriculum meeting the national and international standard of education. After, in-depth insight into the different matters of the designing of curriculum, once approved by the cabinet implemented in all public schools. All the books printed under Punjab text book board as one of the respondent stated: "As government school, we have to follow the curriculum of Punjab Text Book Board and have to abide by government rules and regulation to follow the curriculum". On the other hand, in private school, generally the procedure is not like the public school. They followed the international design curriculum obtained from the renowned education system of the world and printed in Pakistan. Many private schools curriculum is different from the other private schools as the role of manager/director. Principle plays an important role to decide the type of curriculum need to design for the different grades. The private school curriculum is in English language except the language specific subject such as Arabic and Urdu as reported: "To follow the international standard of education and teaching, all curriculums is in English language except Urdu as a Subject".

With respect the content of the curriculum, the private school used their traditional books and ways of teaching by using multi-lingual text. The intention is to complete the text book within prescribed period of time and route system is encouraged. The argument is also supported by Hoodboy (1998) by mentioned that public sector curriculum in teacher centered and based on memory tested exam oriented. Whereas private schools focused on the practical activities which may, enhance the pedagogical skills of the students and 
preferred to use English as a medium of instruction. Although the private schools curriculum is task oriented and multifunctional but due to its diverse nature of designing and planning, it is not align to the set goals and objectives of the desired level of education. Many teachers are just directed to teach the given content without understanding the aim and future implications of the education and learning they are imparting to the students. Malik (1991) also reinforced the finding by imputing the teachers for not giving devotion to the students' learning and lack of understanding about the mission and vision of the school as well aim and objectives of the curriculum.

Teacher-Student Competence: In order to manage the education system and it progression, the competence level of both the students and the teacher are also important to be taken into consideration. In public schools, most of the teacher are used traditional way of teaching and sometimes faced difficulties in the medium of instruction, for instance, they cannot used English language completely due to the varied background of the students as well a teacher themselves. Majority of the student in public schools belongs to lower and lowermiddle socio economic status and good in their native languages. With respect to teachers" competence, it is improving and highly qualified teachers are inducting to improve the standard of education. In private schools, most of the teachers joined immediately after their graduation degree and they are in the process of getting higher education. For gaining experience, they joined private schools and accepted it even on low salary package. Furthermore, it was also find in the study that high qualified teachers are hard to find out on low salaries, therefore private schools had to recruit less competent teacher on low salary.

One the respondent mentioned as: "Our mostly teachers are young female who are firstly enrolled in higher education and secondly have to get married. Due to which to retain one teacher for longer time is the biggest challenge for private schools". As far as language of the curriculum is concern, even in the private schools some of the students are not competent to grasp the foreign language completely. It was especially reported that some of the subject like Islamic studies is difficulty for the study to learn in English. On the other hand, due to exercise of all subjects in English language expect one Urdu course, students are poor in reading and writing own national language. Therefore, both the teachers and students are lacking in some sorts of competence to grasp the multi-dimensional education system. So as most of the female are unmarried when they joined school and after some time due to their marriage they left the job and then after some time period may join it again due to which there is a gap between their professional career and their professional growth has been affected.

Human Resource Management in Schools: Another substantial concerns of the schools is the human resources which comprises of Teachers, helpers, sweepers, principal, administrative support staff, security guards etc. These are the basic potential human resources without them the school cannot function properly. Beside these essential human resources, secondary type of human resources also required for smooth functioning of other activities of school; such as Gardner, Maintainer staff, Library and Lab staff, sports staff etc. all staff in public schools is recruited through proper channel under the government rules. Whereas in the private schools, due to lack of funds, sometime one person has been recruited for multiple task such as teachers may also play a role as library and lab staff as well as for sports activities. Same like that female Attendants for the little kids also do the job of sweeper as well. In private schools, the manager is considered a person, who is at the executive level have his/her own school or owned it as principal or director. All the decision regarding the selection and assigning the specific role and responsibilities to the relevant person is the responsibility of the Manger or director of the school, who owned it.

The manager's task is not just to recruit the potential candidate but also have the responsibility to monitoring and evaluate their performances as well as to identify their needs and problems. On the basis of their performances, managers also have the responsibility to take care of their rewards and facilities for improving their job performance. Beside these roles of human resource management, professional development and retention is very important for the managers. Selecting and recruiting a new teacher is very tedious job as well as it also affects the student's performances and achievements. The study also highlighted that the owner of the private school was in continues struggle and in apprehension of hiring, and retaining their staff by providing them extra bonuses and facilities at school, such as leaves, time flexibility, and reward etc. A study by Ahmed et al. (2013) also highlighted that primary education system is facing the problems of weak supervision, lack of training opportunities for teachers and less paid staff. Mismanagement of resources and 
weak policies leads to poor planning and implementation of curriculum. In private schools most of the teachers are female, and due to our social-cultural norms and existing practices, many of the female have to leave their jobs after getting married.

Issues and Challenges: Every organization has aim and desire to have competent and potential employee to make the organization more effective and competitive. In private schools, human are the vital component and assets of the school and in the current age of competition of private schools, it is necessary to have potential and experience staff and teachers, which is the biggest challenge for private school. As majority of the private schools teachers are young females having no or very less experience, the management has to do their hard work to select the potential employee for school. As the female teacher left their job quickly, again and again manger has to require the new staff and have to give them training and professional skills for performing their job. The schools are lacking in monitoring of education planning and resource management. The public schools have monitoring and evaluation system, but worked in slow pace to bring reforms and update the curriculum. With respect to infrastructure, the public schools are bigger than private schools.

All public schools are constructed for the purpose of education and design accordingly having sufficient play grounds and proper classroom. Whereas private school don't have sufficient space due to opening school in housing building which are not designed for the purpose of education. Due to which students do not have any playground and wide area for their physical activities. Lack of educational planning and management team in private schools is another major due to which every schools is autonomous to design and implement the curriculum and system at their won will and interest. Lacking financial resources in both public and private schools hampered the quality of education and creates difficulties for the teachers to provide their best. Qureshi (2002) stated that teachers in primary schools faced many issues related to their lack of teaching and learning aids as well as less developmental activities for the students.

\section{Conclusion}

The study comprehends the important concerns of educational planning and human resource management in public and private schools in Pakistan. Due to lack of planning, and limited human and financial resources primary education in Pakistan is multi-dimensional and presented in extensive array. It is determined that both the public and private school system have certain strength and feebleness, which not only disturbing the education of children but also hampering the development of the nation education system premeditatedly. Managing human resource in some of the private schools is challenging due to low retention and availability of other better opportunities. Lack of uniformity in curriculum taught in both public and private schools is another challenging factor contributing to insubstantial education system in Pakistan. Employing experienced human resource is one of the thought-provoking responsibilities for the managers within inadequate economic resources. It is indicated that the owner of the private school was in continues struggle and in apprehension of hiring, and retaining their staff by providing them extra bonuses and facilities at school, such as leaves, time flexibility, and reward etc. The study recommended establishing respectable partnership with public and private schools to design universal curriculum and share the expertise of the qualified and experienced human resources. Education should not be taken as business it should be the obligation of the establishments to cultivate a resilient and sophisticated nation.

\section{References}

Ahmad, I., Rauf, M., Rashid, A., Rehman, S. \& Salam, M. (2013). Analysis of the Problems of Primary Education System in Pakistan: Critical Review of Literature. Academic Research International, 4(2), 324-331.

Andarabi, Tahir, Jishnu Das. \& Asim, K. (2002). The Rise of Private Schooling in Pakistan: Catering to the Urban Elite or Educating the Rural Poor? Mimeo, Kennedy School of Government, Harvard University

Ball, D. L. (1990). Prospective elementary and secondary teachers' understanding of division. Journal of Research in Mathematics Education, 21, 132-144.

Coulson, A. (2003). How Markets Affect Quality: Testing the theory of market education against the international evidence. Paper presented at the Educational Freedom and Urban America:

Hoodbhoy, P. (1998). Education and the State: Fifty Years of Pakistan, Oxford University Press, Pakistan. 
Malik, S. R. (1991). The System of Education in Pakistan. National Book Foundation, Islamabad, Pakistan, 1320.

Qureshi, S. (2002). Decentralization to District Level. Ministry of Education, Islamabad, Pakistan, 31-40.

Suleman, Q., Aslam, D. H., Shakir, M., Hussain, I. \& Lodhi, A. M. (2012). Effectiveness of Educational Management System in Elementary and Secondary Education at District Level in Khyber Pukhtunkhwa (Pakistan). American Journal of Scientific Research, 75, 92-116.

Zafar, M. (2003). Fiscal devolution in education. Case study reflecting initial responses, 34-41. 